\title{
Assessment on Cement Production Practice and Potential Cement Replacing Materials in Ethiopia
}

\author{
Abebe Demissew Gashahun \\ Academic Program of Construction Technology and Management, \\ School of Civil and Water Resource Engineering \\ Debre Markos Institute of Technology, Debre Markos University \\ Debre Markos, Ethiopia \\ P.O.Box: 269
}

\begin{abstract}
Cement is the prime ingredient used in the construction industry. Cement consumption has a direct correlation to economic growth and improvement in the living standards of society. Energy and capital intensity nature of the industry necessitate large investments that require a long-term perspective on financing and returns. Besides, production and consumption of cement are mainly subject to economic and construction cycles, resulting in volatility of operating costs and revenues. Addition to that Portland cement clinker production is one of the major sources of $\mathrm{CO}_{2}$ and other greenhouse gases within the contribution of $5 \%$ of the annual global atmospheric $\mathrm{CO}_{2}$ emission. The increasing demand for cement has also provided the desired boost to the cement industry leading to a quite visible growth of additional production capacity and need to find out other cement replacing potential materials. As a result, the study amid to assess on cement production practice and potential cement replacing materials in Ethiopia to reduce the high cost of cement in order to provide sustainable and cost efficient structure for the public and private sectors. It can therefore, be concluded that in Ethiopia there is insufficient supply of cement and there also numbers of alternative cement replacing cementiouse materials like coffee husk ash.
\end{abstract}

Keywords: assessment, cement, production, replacement

DOI: $10.7176 / \mathrm{CER} / 12-1-03$

Publication date: January $31^{\text {st }} 2020$

\section{Introduction}

Now a day's construction has become the most vital components to develop our country and it plays a critical role on social, economy especially to decrease unemployment. When we take about construction, it directly or indirectly related with concrete productions.

Concrete is the most commonly used construction material in the world. It is composite material composed of coarse granular material embedded in a hard matrix of material that fills the space among the aggregate particles and glues them together (Monteiro, 2006). The paste contains cement and water and sometimes-other cementitious and chemical admixtures, whereas the aggregate contains sand and gravel or crushed stone. The paste binds the aggregates together. The aggregates are relatively filler materials, which occupy 70 to $80 \%$ of the concrete and can therefore be expect to have influence on its properties (Hailu, 2011).

Among those ingredients the binder and the costliest and environmental unfriendly element is cement. As a result, the need to reduce the high cost of cement in order to provide sustainable and cost efficient structure for the public and private sectors has strengthens researches in to the use of some locally available construction materials that shall be uses as partial replacement for cement in construction industries. Various research works have been carried out on the binary blends of Ordinary Portland Cement with different cementitious materials such as fly ash, blast furnace slag, silica fume, rice husk ash, coffee husk ash and metakaolin in making cement composites proof to be effective in meeting most of the requirements of environmental friendly, sustainable and durable concrete structures (Obilade, 2014)(Abebe D, 2019).

It is believed that Portland cement clinker production is one of the major sources of $\mathrm{CO}_{2}$ and other greenhouse gases within the contribution of $5 \%$ of the annual global atmospheric $\mathrm{CO}_{2}$ emission (MOI, 2016). In addition to its releases of different gases, its raw material extraction is environmental unfriendly due to degradation and disturbance of existing natural environment. This shows that the cement industry contributes to today's worldwide concern, which is global warming. This endangers the sustainability of the cement industry and that of concrete. The raw materials for the cement production like lime is also being exploited in large amount that may result in running out of them, as it is predicted to happen in some places of the world and in the same way also in Ethiopia (Hailu, 2011).

Coffee husk is usually considered as a type of agriculture waste; as its quantity rises, the treatment/disposal of $\mathrm{CH}$ will become an environmental problem especially around coffee purple centres. (Ayele, 2011).

\section{Cement}

Cement is a hydraulic binder, i.e. a finely ground inorganic materials which, when mixed with water, forms a 
paste which sets and hardens by means of hydration reaction and processes and which after hardening, retains its strength and stability even under water (ESA, 2013).

Cement is the prime ingredient used in the construction industry. Cement consumption has a direct correlation to economic growth and improvement in the living standards of society. Energy and capital intensity nature of the industry necessitate large investments that require a long-term perspective on financing and returns. Besides, production and consumption of cement are mainly subject to economic and construction cycles, resulting in volatility of operating costs and revenues (MOI, 2015).

\subsection{Physical properties of cement}

Specifications for cement place limits on its physical properties. An understanding of the significance of some of the physical properties, finesse, consistency and setting time, is helpful in interpreting results of cement tests. Tests of the physical properties of the cements should be used to evaluate the properties of the cement, rather than the concrete. Cement specifications limit the properties with respect to the type of cement. Cement should be sampled in accordance with ASTM C 183.

\subsection{Cement production in Ethiopia}

In terms of consumption and production of cement in the world, China leads the way due to the large-scale developments and infrastructure buildup projects that the Chinese government is undertaking. According to 2014 estimates, the Chinese production was 2430 Million tons per annum (see Table 1) covers around 57.8\% of world total while the second closest rival, India covers around 6.7\% (MOI, 2015).

The construction industry is giving a special focus in the policies of the many developing countries. In Ethiopia, due to its critical role in the overall economic development, the cement industry is identified as one of the areas of the first and second Growth and Transformation Plan (GTP) as a sector of special consideration. Unlike the case in developed and emerging economics, concrete industry has not yet emerged as a significant consuming of cement. The energy cost of Ethiopian cement firms account nearly 50-60\% the total production structure as contrast to 30 to $40 \%$ of global standards (Aklilu, 2016).

In Ethiopia, Given the vast geographical size and massive population, various construction activities are being undertaken by the Federal Government, Regional Governments, Public Sector Undertakings and other organizations, including the private sector that generates a huge demand for cement. The major factors that are causing a huge demand for cement are heavy investments on housing projects, universities, infrastructures, power generation plants and irrigation, industrial zones, airport fields, railways and road construction projects.

Due to the rapid economic growth in general and construction activities in particular, cement consumption has risen by an average growth rate of $30 \%$, well above the growth rates seen during this period for both overall GDP growth (11\%) and the construction sector $(10 \%)$ and for least five years it is on the breakeven point of demand and supply perspectives. This increase in cement consumption which is triggered by huge projects in the construction sector has led to extensive private sector domestic and foreign investments to establish cement manufacturing industries (MoFD, 2010).

In Ethiopia, Italians established the first cement factory in 1936 during the five-year fascist occupation of the Country (Getaneh, 2010). This was the Dire Dawa cement factory. Due to the rise in concrete construction in Ethiopia, the demand for cement has been growing since then and in 2008 there were four cement plants with a combined production capacity of about 2.85 million metric tons per year as reported by Ethiopian investment agency. Currently there are around 26 functional cement factories with total production capacity of 26.21 million tones.

Currently, in Ethiopia, cement is mainly produced in three forms: Ordinary Portland Cement (OPC), Portland Pozzolana Cement (PPC) and Portland lime cement (PLC). OPC is the most common type of cement in general use around the world because it is a basic ingredient of concrete. PPC is ordinary Portland cement blended with pozzolana materials like fly ash, burnt clays, ash from burnt plant material or silicious earths, either together or separately. PLC is produced by incorporated huge percentage of lime and currently it is produced by Messebo cement factory. In Ethiopia, approximately 18 percent of the total production was historically OPC, while 81.1 percent was PPC and 0.9 percent of PLC (MOI, 2016). The construction industry is growing in a shocking rate. Ethiopia historically has low cement per capita consumption as low as $39 \mathrm{Kg}$ in 2011 whereas it reached $62 \mathrm{~kg}$ in 2014 which is still low compared to the global average of $500 \mathrm{~kg} /$ year (MOI, 2015). 
Table 1 The top eleven nations in the world in production of cement (MT)

\begin{tabular}{|l|l|l|l|l|l|l|}
\hline No. & Country & $\mathbf{2 0 1 0}$ & $\mathbf{2 0 1 1}$ & $\mathbf{2 0 1 2}$ & $\mathbf{2 0 1 3}$ & $\mathbf{2 0 1 4}$ \\
\hline 1 & China & 1880 & 2080 & 2220 & 2350 & 2430 \\
\hline 2 & India & 224.7 & 240.5 & 246.7 & 272.0 & 300.0 \\
\hline 3 & USA & 66.5 & 67.9 & 74.4 & 82.7 & 92.8 \\
\hline 4 & Iran & 61.6 & 66.4 & 73.2 & 76 & 78 \\
\hline 5 & Brazil & 59.1 & 64.1 & 68.0 & 73.3 & 77.9 \\
\hline 6 & Turkey & 66.2 & 667.8 & 69.0 & 71.0 & 73.5 \\
\hline 7 & Russia & 50.4 & 56.1 & 60.0 & 63.0 & 65.0 \\
\hline 8 & Egypt & 48.0 & 45.4 & 55.2 & 58.0 & 62.0 \\
\hline 9 & Japan & 56.6 & 56.4 & 59.0 & 60.0 & 60.0 \\
\hline 10 & Vietnam & 50.5 & 52.0 & 47.0 & 48.4 & 51.2 \\
\hline 11 & South Korea & 47.4 & 48.3 & 48.9 & 48.4 & 48.1 \\
\hline 12 & Ethiopia & 2.08 & 3.55 & 1.91 & 2.14 & 6.11 \\
\hline
\end{tabular}

Source (MOI, 2015)

According to Getaneh (2010), cement industry needs high capital investment. It is also energy intensive. It is highly dependent on power and transport. Some of the fundamental elements to be considered in cement production investment are:

\section{A. Cost of Production}

The cement industry is one of the highest energy-intensive industries in the world, with fuel and energy costs typically representing 30-40\% of total production costs. Raw material costs represent the second-largest percentage of cement manufacturers' cost structures. The abundance of these raw materials in most parts of the country is reliable. The distribution of cement factories throughout the country justifies the availability of sample raw materials for the cement industry.

\section{B. Raw Materials}

The primary raw materials used for cement production are limestone, clay, chalk, marl, and others, significant quantities of which are continuously quarried to service the demand for cement. Alternative materials have been sourced to substitute for traditional natural raw materials. The industry currently uses large quantities of blast furnace slag, power station fly ash, silica fume, and natural pozzolana and limestone fines, mainly to substitute for natural raw materials in the production process of blended cement such as GGBS and PFA. The use of these alternative materials has significant positive environmental and economic benefits. The needs to quarry primary raw materials are reduced, energy consumption in cement production is cut, and over all reductions in emission of dust, $\mathrm{CO}_{2}$ and acid gases are attained. In some applications, the performance of concrete can be enhanced when these alternative materials complement Portland cement clinker.

\section{Energy/Power}

Cement manufacturing is an energy-intensive process. The specific thermal energy consumption of a cement kiln varies between 3,000 and 7,500 million joules per ton of clinker, depending on the basic process design of the plant. The specific electrical energy consumption typically ranges between $90-130 \mathrm{kWh}$ and $60-130 \mathrm{Kg}$ of fuel oil per ton of cement.

According to MoFD (2010),"the cement industry was expected to produce $4.7 \mathrm{mln}$ tons of cement per year in order to meet the demand in 2015, 27 mln tons per years. However, the industry achieved an output of only $11.17 \mathrm{mln}$ tons of cement in the year 2009/2010". This result suggests the need to increase the production and supply capacity of cement in order to meet the need of the fast growing construction industry.

Table 2 Cement Consumption in Ethiopia (in mln MT)

\begin{tabular}{|l|l|l|l|l|l|l|l|l|}
\hline Year(GC) & $\mathbf{2 0 0 9} / \mathbf{1 0}$ & $\mathbf{2 0 1 0} / \mathbf{1 1}$ & $\mathbf{2 0 1 1} / \mathbf{1 2}$ & $\mathbf{2 0 1 2} / \mathbf{1 3}$ & $\mathbf{2 0 1 3} / \mathbf{1 4}$ & $\mathbf{2 0 1 4} / \mathbf{1 5}$ & $\mathbf{2 0 1 5} / \mathbf{1 6}$ & $\mathbf{2 0 1 6} / \mathbf{1 7}$ \\
\hline Consumption estimate & 2.7 & 9.34 & 13.6 & 13.6 & 17 & 27 & 29.2 & 31.2 \\
\hline Actual production & 1.87 & 2.08 & 3.55 & 1.91 & 2.14 & 6.11 & 11.3 & 12.9 \\
\hline
\end{tabular}

Sources (CSA, 2016; MOI, 2017)

\subsection{Pozzolana}

The modern concrete technology uses different types of admixtures in order to enhance the properties of the fresh and hardened concrete. Mineral admixtures are one of these admixtures used in concrete for a variety of purposes. They may be found naturally or artificially. These admixtures can be divided into three main categories, which are pozzolana, cementitious and non-reactive materials.

\subsubsection{Pozzolana materials}

A pozzolana is a siliceous or aluminosiliceous material that, in finely divided form and in the presence of moisture, chemically reacts with the calcium hydroxide released by the hydration of Portland cement to form calcium silicate hydrate (CSH) and other cementitious compounds (H. Kosmatka, 2003). Clay and shale, opalinc chert, diatomaceous earth, and volcanic ash are an example of natural Pozzolana while fly ash, blast furnace slag, silica 
fume, rice husk ash, coffee husk ash and metakaolin are example of artificial Pozzolana. Most of the pozzolana in use today are mainly by-product materials that are widely available. Because of the diversity of pozzolana, their chemical composition also varies. Therefore, classifying Pozzolana only depending on their chemical composition would be difficult. For this reason, ASTM C 618 classifies Pozzolana depending on performance basis classified as class $\mathrm{F}$ and class $\mathrm{C}$.

The reason behind using Pozzolana is the improvement found on both the fresh and hard concrete. Lowering of the heat of hydration and thermal shrinkage, increase in water tightness, reduction in the alkali aggregate reaction, resistance to sulfate attack, better workability, and cost efficiency are some of the improvements achieved by using Pozzolana blended with Portland cement (Hailu, 2011).

Fly ash is a supplementary cementitious material in concrete and a byproduct of the combustion of pulverized coal in electric power generating plants. It is a fine-grained material consisting primarily silicate glass containing silica, alumina, iron, and calcium. Minor constituents are magnesium, sulfur, sodium, potassium, and carbon. Deferent scholars sagest 10-15\% of fly ash cement replacements are recommend (Marsh, 1997).

Blast-furnace slag is a byproduct of iron manufacture. It is non-metallic hydraulic cement consisting essentially of silicates and aluminosilicates of calcium developed in a molten condition simultaneously with iron in a blast furnace. The molten slag at a temperature of about $1500{ }^{\circ} \mathrm{C}$ is rapidly chilled by quenching in water to form a glassy sand like granulated material which is one of the recommended cement replacing materials. Due to this GGBFS in the presence of water and an activator $\mathrm{NaOH}$ or $\mathrm{CaOH}$ supplied by Portland cement, hydrates and sets in a manner similar to Portland cement (H. Kosmatka, 2003)

Silica fume is a byproduct material that is use as a pozzolana. This byproduct is a result of the reduction of high-purity quartz with coal in an electric arc furnace in the manufacture of silicon or ferrosilicon alloy. Silica fume is use in amounts between $5 \%$ and $10 \%$ by mass of the total cementitious material. It is use in applications where a high degree of impermeability is need and in high strength concrete (H. Kosmatka, 2003).

Highly reactive metakaolin has recently become available as a very active pozzolana material for use in concrete. Unlike fly ash, slag, or silica fume, this material is not a byproduct but is manufacture from high-purity kaolin clay by calcination at temperatures in the region of 700 to $800^{\circ} \mathrm{C}$. Unlike silica fume, which contains more than $85 \% \mathrm{SiO}_{2}$, highly reactive metakaolin contains equal proportions of $\mathrm{SiO}_{2}$ and $\mathrm{Al}_{2} \mathrm{O}_{3}$ by mass $(\mathrm{H}$. Kosmatka, 2003).

Bagasse is a cellulose fiber remaining after the extraction of the sugar-bearing juice from sugarcane. The bagasse ash is about $8-10 \%$ of the bagasse and contains unburned matter, silica and alumina. Sugarcane bagasse ash as described before contains silica, which is the most important component of cement replacing materials. It is also finding in large amount as a byproduct in sugar factories. Some studies show that replacement of OPC by bagasse ash from 5 to $10 \%$ results in a better compressive strength than that of the control mortar (Hailu, 2011).

Rise husk ash which is an agricultural by-product, has been report to be a good pozzolan by numerous researchers. They investigated the use of RHA to reduce temperature in high strength mass concrete and got result showing that RHA is very effective in reducing the temperature of mass concrete compared to OPC concrete (Obilade, 2014).

\subsubsection{Coffee husk}

Coffee husk is the most abundantly available agro industrial waste produced during the pulping action of the coffee cherries to obtain coffee beans in many coffee-producing areas of the tropics including Ethiopia.

The use of different cement replacing materials has become a common practice in the construction industry. Most of these cement replacement materials are byproducts of different industries and agricultural wastes. Blast furnace slags, silica fume, fly ash, bagasse ash and rice husk can be sited as an example. Coffee husk ash has also been founded to have such pozzolana property (Abebe D. 2019).

Owing to considerable use of cement and concrete material, the natural material resources related to the construction industry has been continuously reduces in recent years. However, for each country particularly for developing country like Ethiopia, concrete is the most important material for fundamental and public constructions. Thus, an innovative and alternative concrete material, which possesses feasibility and practicality, is critical and significant for mitigating environmental impact and promoting energy-saving performance.

2.3.2.1. Pozzolana property of coffee husk ash

As described in previous sections Pozzolana are siliceous or siliceous and aluminous materials which alone possess little or no cementitious value but which will, in finely divided form in the presence of moisture, react chemically with calcium hydroxide at ordinary temperature to form compounds possessing cementitious properties $(\mathrm{H}$. Kosmatka, 2003). CHA was also tested to have such property. It acts as a pozzolanic material when added to cement because of its silica $\left(\mathrm{SiO}_{2}\right)$ and aluminate content, which reacts with free lime release during the hydration of the cement and forms additional CSH as a new hydration product Abebe D. 2019). 
Table 3: Major chemical composition of cements raw materials and pozzolana

\begin{tabular}{|l|l|l|l|l|l|l|l|l|}
\hline Component & $\mathbf{S i O}_{2}$ & $\mathbf{A l}_{2} \mathbf{O}_{3}$ & $\mathbf{F e}_{2} \mathbf{O}_{3}$ & $\mathbf{C a O}$ & $\mathbf{M g O}$ & $\mathbf{S O 3}$ & $\mathbf{K}_{2} \mathbf{O}$ & $\mathbf{N a}_{2} \mathbf{O}$ \\
\hline Limestone & 2.68 & 0.62 & 0.46 & 51.85 & 1.94 & 0.03 & 0.05 & 0.02 \\
\hline Sandy Cay & 81.56 & 11.29 & 1.79 & 0.12 & 0.09 & 0.05 & 0.14 & 0.03 \\
\hline Clay & 65.18 & 21.91 & 3.36 & 0.11 & 0.08 & 0.06 & 0.19 & 0.04 \\
\hline Iron ore & 14.88 & 16.79 & 57.74 & 0.12 & 0.56 & 0.04 & 0.04 & 0.03 \\
\hline Shale & 61.10 & 16.42 & 7.01 & 1.02 & 2.34 & 0.01 & 4.12 & 1.65 \\
\hline Sand & 94.70 & 2.90 & 0.24 & 0.35 & 0.13 & 0.01 & 0.60 & 0.21 \\
\hline Bauxite & 3.11 & 57.59 & 15.74 & 4.16 & 0.16 & 0.29 & 0.08 & 0.08 \\
\hline Gypsum & 4.31 & 0.34 & 0.14 & 31.19 & 0.11 & 43.88 & - & - \\
\hline Fuel Ash & 57.20 & 17.36 & 9.11 & 3.95 & 1.80 & 3.40 & 0.78 & 2.50 \\
\hline Bagasse Ash & 65.58 & 5.87 & 4.32 & 1.78 & 1.23 & 0.18 & 6.41 & 1.02 \\
\hline CHA & 16.55 & 17.18 & 3.98 & 5.68 & 1.12 & 1.9 & 19.3 & 1.84 \\
\hline
\end{tabular}

Source (Adisu, 2014; Hailu, 2011, Abebe D.2019)

2.3.2.2. Coffee husk ash as cement replacing material

These days' sustainability plays the major role in every aspect of human activities. Many technologies ended because they were not in harmony with the idea of sustainable development. Sustainability is concerned about the world we will be leaving behind for future generations, that is, to our children and their children. It focuses on the social, environmental and economic issues of human activities.

The reduction of Portland cement in concrete can be achieved by replacing it with different supplementary cementitious materials that are a by-product of another industry. Fly ash, silica fume, GGBFS, etc. have been use for this purpose successfully. Coffee husk ash as described before contains silica, which is the most important component of cement replacing materials. It also found in large amount as a byproduct of agriculture. Despite this abundance and silica content, relatively little was been done to examine the potential of this material for concrete production. Even though little, the conducted researches confirm the suitability of this material for concrete production by replacing cement in some percentage for mortar and concrete. When CHA used as cement replacing material, it results in some improvement on the properties of concrete. At 28 days, concrete containing coffee husk ash at $10 \%$ replacement showed compressive strength higher than the control concrete (Abebe D. 2019).

2.3.2.3. Availability of coffee husk in Ethiopia

Ethiopia is the seventh largest coffee producer worldwide and ranked ninth in coffee export. And also the largest coffee producer in Africa: Around 400,000 tons per annual - all of it Arabica which is processed in both method (Shimelis, 2011). According to the (ICO, 2016a), the fourth international coffee conference (ICC) which was held in March 2016 at Addis Ababa, report forecasted for Ethiopian coffee export quantity for 2016 was 230,000 tons. Beyond this the fifth international coffee conference (ICC) that was held in February 2017 at Addis Ababa, report shows that Ethiopia export only $40 \%$ of its total production. As a result, the reaming $60 \%$ of coffee is use by local market. Coffee husks, which are produce through dry method, since for every $1 \mathrm{~kg}$ of coffee beans produced, approximately $1 \mathrm{~kg}$ of husks be generated (1:1 ratio) (Franca, 2015; Gonzalez, 2010; Shimelis, 2011).

Table 4 Total coffee production and associated residue from 2009-2016

\begin{tabular}{|l|l|l|l|l|l|l|l|}
\hline Production years & $\mathbf{2 0 0 9} / \mathbf{1 0}$ & $\mathbf{2 0 1 0} / \mathbf{1 1}$ & $\mathbf{2 0 1 1} / \mathbf{2 1 2}$ & $\mathbf{2 0 1 2} / \mathbf{1 3}$ & $\mathbf{2 0 1 3} / \mathbf{1 4}$ & $\mathbf{2 0 1 4} / \mathbf{1 5}$ & $\mathbf{2 0 1 5} / \mathbf{1 6}$ \\
\hline Total production (tons)*10 & 341 & 405.7 & 482.89 & 579.468 & 695.362 & 831 & 945.3 \\
\hline Residue (dry base) (tons)*10 & 341 & 405.7 & 482.89 & 579.468 & 695.362 & 831 & 945.3 \\
\hline $\begin{array}{l}\text { Equivalent ash productions } \\
\text { (tons) }\end{array} 1^{3}$ & 62.403 & 74.243 & 88.369 & 106.043 & 127.251 & 152.073 & 172.990 \\
\hline
\end{tabular}

Source (CSA, 2016)

From the tables 4 it is possible to summarize that coffee processing and coffee bean production produce huge amounts of coffee husk that can be converted in to cementiouse materials in factory level.

\subsection{Advantages of $\mathrm{CHA}$ as partial replacement of cement}

Coffee husk which is the most abundant and nonedible agricultural waste has the following advantages while using as partial replacement of cement for concrete productions.

\section{A. Environmental advantages}

The cement manufacturing industry is under higher scrutiny these days because of the large volumes of $\mathrm{CO}_{2}$ emitted. Actually, this industrial sector is thought to represent 5-7\% of the total $\mathrm{CO}_{2}$ anthropogenic emissions. Concern over the impact of anthropogenic carbon emissions on the global climate has increased in recent years due to growth in global warming awareness. In addition to the generation of $\mathrm{CO}_{2}$ the cement manufacturing process produces millions of tons of the waste product cement kiln dust each year contributing to respiratory and pollution health risks .To produce 1 tons of clinker, the typical average consumption of raw materials is 1.52 tones (Eštoková, 2012). 
The amount of clinker needed to produce a given amount of cement can be reduced by the use of supplementary cementitious materials such as coal fly ash, slag, and natural Pozzolanas (e.g., rice husk ash, coffee husk ash and volcanic ashes). The addition of these materials into concrete not only reduces the amount of material landfilled (in case of industrials byproducts), but also reduces the amount of clinker required per ton of cement produced.

In the last years, coffee husk has attracted great attention since they are generated in large amounts every year and represent a great pollution hazard if discharged into the environment.However, as these residues are derived from coffee beans, they are expected to have properties similar to these beans and could be therefore exploited for different industrial applications. In this sense, some alternatives have been proposed to reuse these coffee residues (Mussatto, 2014). Coffee husks contain some amount of caffeine and tannins, which can make it toxic and slow degradation in nature and result in the disposal problem. Currently, the coffee pulp is discharged into local streams and rivers where it tends to clog, forming a putrescent mass and producing a highly acidic effluent which pollutes the water, destroying aquatic life and generating an offensive odour. Recovery of this pulp for partial cement replacement use would require collecting the residues as they are discharged from the pulping machine and processing them to greatly reduce the moisture content (Ayele, 2011).

Therefore, replacing the portion of Portland cement with coffee husk ash can substantially reduce the environmental impact of concrete associated with cement production like consumption of raw materials and energy use as well as emissions to air and avoiding environmental pollution due to coffee husk wastes.

\section{B. Energy saving}

The cement industry plays a significant role in global energy consumptions. Worldwide the cement industry is one of the most energy intensive sectors in which energy represents $40 \%$ of the total production cost. The energy consumption in cement manufacturing is mainly related to the production methods that is wet methods consume more energy than dry methods. For instance in dry method $1450{ }^{\circ} \mathrm{C}$ of temperature is needed for the production of clinker which accounts $97.2 \%$ of the total and the remaining is for finishing and raw materials grinding with the share of $0.9 \%$ and $1.9 \%$ respectively (MOI, 2015, 2016).

\section{Reduction of $\mathrm{CO}_{2}$ emission}

Sustainable development of cement and construction industry in relation to environmental impact is one of the biggest challenges. The production of one ton of Portland cement release approximately one ton of $\mathrm{CO}_{2}$ to the atmospheres in the manufacturing process. The cement industry contributes about $5 \%$ of the total atmospheric $\mathrm{CO}_{2}$ emissions globally (Yossef, 2016). As a matter, of fact we are now concerned by the environmental impact of civil engineering structures. Judicious use of CHA as a partial replacement of cement can result a significant result in reduction of $\mathrm{CO}_{2}$ footprint of concrete structures. Most of the $\mathrm{CO}_{2}$ emissions and energy use in the cement industry are related to production of the clinker; $63 \%$ of the $\mathrm{CO}_{2}$ emitted during cement production comes from the calcination process, while the rest $(37 \%)$ is produced during the combustion of fossil fuels to feed the calcination process (Mercier, 2010).

\section{Economic advantages}

The production of cement is energy intensive, depends on the availability of raw materials near to the cement manufacturing area and nature disturbances due to extraction of raw materials. The process is mainly classified into three, the raw material preparation process, the clinker burning process and the finish grinding process. Off all this processes, clinker burning is the most energy intensive process, accounting for about more than $97.3 \%$ of the fuel consumed and about $30 \%$ of the electric power consumption and the rest about $40 \%$ of the electric power is consumed by the finish grinding process and about $30 \%$ by the raw material preparation (Hailu, 2011; MOI, 2015, 2016). Fuel costs are a large part of the manufacturing cost of the cement industry, making cement plants to have aggressive energy consumption.

\section{Conclusions}

The future demand of Ethiopia for cement, like many other construction materials is a function of a number of interrelated variables. Some variables that is essential in determining the magnitude and trend of demand for cement are-

The overall economic development level and growth trend of the country,

$>$ The pattern and growth trend of the construction industry,

$>$ Expected technological changes that affect the structure of the construction industry,

$>$ Government policies and regulations that have impact on the future level and trend of construction activities, and

$>$ Size of population and its growth rate etc.

Generally, review of sources put forward that Ethiopia has greater cement demand driver's potential for higher cement consumption to come mainly due to continued and robust GDP growth. Some of those demand driver's factors are; - Political stability, increasing per capita income and emergence of middle class, increasing government capital budget expenditures, rapid urbanization $(4.3 \%)$, high rate of population growth $(2.6 \%)$, 
significant housing shortages, large infrastructural gap and development of industrial parks (29.37 million square meters). Besides, in order for the country to realize the dream to join middle-income countries by 2025 , several other mega projects will be undertaken in years to come. The total estimated annual local production is $26.21 \mathrm{mln}$ of MT. but our country's production capacity is around $60 \%$ of their annual estimated production capacity. As a result, the country's' annual production is $15,726,000 \mathrm{MT}$.

Generally, the general trend of cement production and consumption in Ethiopia has been increasing. Yet the prevalence of underutilized cement production capacity remains outstanding challenge for Ethiopian's cement industry. Currently, the average cement production capacity utilization rate in the country is about $50 \%$. The level of capacity utilization even compared to global average of 60 to $70 \%$ or recommended acceptable optimum production capacity utilization rate that ranges between 80 to $85 \%$ is sustainably low Recommendations

\section{REFERENCES}

Abebe, D. Fekadu F. and Sintayehu A. (2019). Partial replacement of cement by coffee husk ash for c-25 concrete production.. Journal of Civil Engineering, Science and Technology Volume 10, Issue 1, April 2019

Aklilu, D. (2016). Strategic coorporation among cement, concrete and energy industries:agenda for action. Paper presented at the Proceeding of irst annual east africa cement, concrete and energy summit, Addis Ababa, Ethiopia.

Ayele, K. (2011). Bioethanol production and optimization test from agricultural waste: the case of wet coffee processing waste (pulp). (MSc.), Addis Ababa University.

CSA, F. (2016). Report on large and medium scale manfacturing and electricity industry service. Addis Ababa.

ESA. (2013). Cmposition, Specification and Conformity Criteria for common cement, frist edtion (Vol. CES 28). A.A: ESA.

Eštoková, A. (2012). Environmental impacts of cement production. Technical University of Košice,. Retrieved from http://ena.lp.edu.ua

Getaneh, G. (2010). Cement demand in Ethiopian construction industry: current practices and future trends. Retrieved from Addiss Ababa:

H. Kosmatka, B. K., and William C. Panarese. (2003). Design and Control of Concrete Mixtures, EB001, 14th edition, . Skokie, Illinois, USA,: Portland Cement Association, .

Hailu, B. (2011). Bagasse ash as a cement replacing material. (MSc.), Addis Ababa Institute of Technology., Addis Ababa:.

Marsh, B. K. (1997). Design of normal concrete mixes (Second edition. ed.): Building Research Establishment.

Mercier, A. (2010). Energy Efficiency and CO2 Emissions: Prospective Scenarios for the Cement Industry. Retrieved from Netherland

MoFD, F. (2010). Groth and Transformation Plan I 2010/11-2014/15. Addis Ababa.

MOI, F. (2015). Ethiopian Cement Industry Development Strategy 2015-2025. Adama Science and Technology University.

MOI, F. (2016). Energy Efficiency imprvement in National Cement Factory. Addis Ababa, Ethiopia: Construction,Cement and Chemecal Institution of Ethiopia

MOI, F. (2017). Actule cement productions capcity of local cement plants Retrieved from Addis Ababa

Monteiro, P. K (2006). Concrete Microstructure, Properties, and Materials, Third Edition. . California:: Department of Civil and Environmental Engineering University of California at Berkeley.

Mussatto, S. I. (2014). Chemical, Functional, and Structural Properties of Spent Coffee Grounds and Coffee Silverskin. Springer Science+Business.

Obilade, I. O. (2014). Use of Rice Husk Ash as Partial Replacement for Cement in Concrete. EAAS, 5(4), 11-16.

Shimelis, A. (2011). A. optimization of coffee wastes for the cultivation of pleurotus ostreatus., Addis Ababa University. 